\title{
Rekonstruksi 3D Untuk Model Wajah Virtual Akademik Menggunakan Sensor Kinect 2
}

\author{
Siti Sofia Rani a,1,*, Adhi Prahara a,2 \\ a Program Studi Teknik Informatika Universitas Ahmad Dahlan, Jl.Ringroad Selatan, Daerah Istimewa Yogyakarta 55191,Indonesia \\ 1 siti1400018038@webmail.uad.ac.id *; ${ }^{2}$ adhi.prahara@tif.uad.ac.id; \\ * Penulis Korespondensi
}

\begin{abstract}
Massive multiplayer online game (MMOG) seperti World of Warcraft, Aion atau Second Life telah mendapatkan perhatian luar biasa pada perkembangan game vitual. Salah satu kelebihan MMOG pada permainan virtual setiap pemain dapat berkomunikasi secara langsung yang diwakili dengan karakter visual tiga dimensi. MMOG juga mendukung grafik permainan pada komputer hingga permainan yang digunakan menggunakan karakter visual tiga dimensi menjadi terlihat nyata. Penelitian ini memanfaatkan alat sensor kinect 2 dan Microsoft Kinect yang membantu untuk merekam avatar tiga dimensi yang dapat dipersonalisasikan. Dari perkembangan alat sensor yang bernama Kinect 2 sensor dapat mempermudah rekontruksi 3D untuk model wajah pada avatar permainan virtual dan diproses menggunakan teknik modeling 3D hingga visual dari hasil sensor Kinect 2 menggambarkan tampak nyata dari player dalam bentuk visual. Penelitian ini menghasilkan rekontruksi 3D untuk model wajah pada avatar game virtual akademik menggunakan sensor Kinect 2. Hasil pengujian SUS untuk uji modelling dan visual avatar 3D menghasilkan nilai rata-rata 41,6 dari sekala 5, maka masuk kategori acceptable yang artinya aplikasi dapat diterima.
\end{abstract}

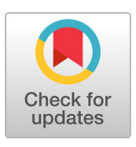

\section{KEYWORDS}

Kinect 2

Modeling 3D

MMOG

Game Virtual

\section{Pendahuluan}

Massive multiplayer online games (MMOG) seperti World of Warcraft, Aion, atau Second Life telah mendapatkan perhatian luar biasa [1]. Dalam permainan ini, jutaan pemain, masing-masing diwakili oleh karakter virtual dikenal sebagai avatar bertemu dengan dalam dunia maya tiga dimensi. Karena pengguna harus dapat dibedakan satu sama lain, setiap pengguna harus memiliki avatar yang unik. Kebanyakan MMOG menawarkan editor karakter di mana pemain dapat memilih avatarnya dari serangkaian model yang ada [2]. Avatar ini dapat lebih dikustomisasi menggunakan antarmuka pengguna sederhana yang memungkinkan pengguna untuk berubah bentuk atau untuk menyertakan tekstur atau model yang disesuaikan.

Apabila grafik dalam permainan komputer menjadi lebih realistis dan focus dari permainan berubah menyerupai kehidupan nyata, permintaan untuk avatar fotorealistik, yang menyerupai pengguna sendiri itu sendiri dan meningkat. Pada saat ini editor game avatar hanya menawarkan kebebasan berekspresi yang terbatas bagi pengguna, sehingga menyebabkan hampir tidak mungkin bagi pengguna untuk membuat virtual clone di dunia online. Selain pengguna dalam game online, avatar 3D yang dipersonalisasi juga penting dalam aplikasi mobile seperti simulasi penuaan atau salon kecantikan 3D digital.

Berdasarkan penelitian [3] menyatakan bahwa sensor Microsft Kinect sangat cocok untuk merekam avatar 3D yang dapat dipersonalisasi. Karena harga pasar yang rendah dan penggunanya yang luas. Objek sangat penting untuk diperhalus agar modelling terlihat realistic, pada aplikasi blender terdapat tools untuk memperhalus objek yaitu dengan menggunakan tools shading. Cara penggunaannya sangat mudah hanya perlu seleksi objek kemudian pada tools shading pilih smooth.

Blender adalah aplikasi modelling, rendering dan animasi 3D yang kini menjadi primadona. Ukuran yang (50 MB), kecepatan, kemudahan dan kelengkapan bisa mengalahkan 3D Max dan Autodesk Maya [4]. Selain Modelling dan animasi 3D Blender juga untuk video editing, video effects, image retouching, game development. 
Berdasarkan uraian diatas penelitian tertarik untuk melakukan penelitian membuat rekonstruksi 3D untuk model wajah pada avatar game virtual akademik menggunakan sensor kinect 2 .

\section{Kajian Pustaka}

\subsection{Kajian Peneliti Terdahulu}

Pada penelitian ini tidak terlepas dari kajian terdahulu yang digunakan sebagai acuan dalam penelitian ini. Berikut kajian terdahulu yang di ambil :

Penelitian yang dilakukan oleh Badirun dari STMIK Handayani, jurusan Program Pascasarjana Sistem Komputer. Pada penelitian tersebut menjelaskan sistem keamanan rumah berbasis Kinect, pada penelitiannya membahas mendeteksi wajah maupun seluruh tubuh manusia dengan metode berbasis Kinect yang bertujuan menghasilkan sistem yang dapat mendeteksi keamanan rumah serta mengimplementasikan rumah berbasis Kinect. Pada penelitian Badirun Basir sistem tersebut menggunakan kamera Kinect. Pada penelitian ini menghasilkan Kinect melakukan koneksi ke server dan kemudian mengirimkan RGB ke server pada port 3200 dan dept image melalui poth 3207, server menerima gambar RGB yang masuk pada port 3200 dan dept image melalui port 3207, server menunggu request dari client apabila server akan mengirim tiga data berupa gambar RGB, depth image dan data [5].

Penelitian yang dilakukan oleh jicao Pada penelitian tersebut menjelaskan bagaimana cara bermain game dan cara berinteraksi dengan pemain menggunakan Kinect agar seolah-olah berada dalam game tersebut. Meode yang digunakan adalah rekosntruksi 3D yang bertujuan untuk membuat avatar yang dihasilkan Kinect secara alami, kemudian hasil dari penelitian ini menciptakan ilusi bahwa peserta jarak jauh berada di dalam ruangan yang sama dalam game [6].

Penelitian yang dilakukan oleh henry dari jurnal internasional penelitian robotika. Pada penelitian tersebut menjelaskan tentang RGB-D camera bisa membangun dan memvisualisasikan peta 3D. Sensor Kinect menggabungkan beberapa perangkat sensor, seperti depth,warna kamera,memiliki empat mikrofon yang memberikan pengambilan full body dalam bentu 3D, dan memiliki kemampuan dalam pengenalan suara. Pada penelitian Peter Henry menggunakan RGB-D dan sensor Kinect untuk mendeteksi peta, kamera RGB-D dapat menangkap gambar RGB (visual) Bersama dengan kedalaman per piksel. Sedangkan sekarang system sensor dengan kemampuan ini sudah dibuat khusus selama bertahuntahun, hanya sekarang dibuat dalam bentuk yang menarik [7].

Penelitian yang dilakukan dari Universitas Beijing. Pada penelitian tersebut menjelaskan tentang penetapan model 3D di dunia nyata, rekonstruksi model 3D dapat dibagi menjadi dua jenis yaitu rekosntruksi berbasis tekstur dan berbasis rekonstruksi kedalaman. Pada penelitian Jing Zhang menggunakan sensor Kinect karena biaya yang murah dan kecepatannya tinggi. Kinect memiliki tiga lensa di depan, kamera warna di tengah dan dua kedalaman kamera di kedua sisi [8].

Penelitian yang dilakukan oleh Ratna Siv dari Universitas Gadjah Mada, Jurnal Teknik Informatika. Pada penelitian tersebut menjelaskan tentang rekonstruksi wajah manusia menggunakan sensor Kinect, pemindai 3D yang terjangkau saat ini adalah Microsoft Kinect dikenal sebagai add-on sensor gerak untuk game Xbox, dengan menggunakan sensor kedalaman Kinect 2 wajah manusia dimungkinkan untuk dibangun, namun Kinect saja tidak menghasilkan kualitas yang baik dapat menghilangkan detail wajah 3D karena itu pengoptimalan dan peningkatan diperlukan [9]. Penelitian menggunakan metode Jet Smooth dan gri simplift, oriental normal, bilateral smooth,permukaan poisson. Penelitian ini bertujuan untuk merekonstruksi model wajah manusia 3D dengan menggunakan bidikan tunggal kedalaman 3D atau point cloud dari kedalaman sensor Microsoft Kinect 2 dan kemudian rekosntruksi dengan permukaan poisson. Dari penelitian ini menghasilkan hasil zoom clound titi RGB asli terlihat seperti model 3D dan hasil aplikasi Microsoft 3D. Menggunakan Kinect 2, 3D yang terjangkau model manusia dapat direkonstruksi hanya dalam beberapa detik dengan menggunakan rekonstruksi 3D dan poisson rekonstruksi permukaan adalah solusi untuk 3D dari titik 3D yang dapat oleh Microsoft Kinect 2.

\subsection{Landasan Teori}

\subsubsection{Microsoft Kinect}

a. Rekonstruksi 3 Dimensi

Rekonstruksi 3 dimensi merupakan rekayasa membuat gambar 3 dimensi dengan menggabungkan beberapa gambar 2 dimensi yang ditangkap kamera [10]. Salah satu metode rekonstruksi 3 dimensi adalah 
dengan melakukan proses registrasi terhadap point clouds. Registrasi sendiri merupakan proses untuk menentukan hubungan titik per titik antara dua buah cintra atau lebih yang diambil dari tempat yang sama di waktu yang berbeda, atau dari sudut pandang yang berbeda serta kondisi pencitraan yang berdeda.

b. Virtual Akademik

Virtual adalah teknologi yang membuat pengguna dapat berinteraksi dengan suatu lingkungan yang disimulasi oleh computer, suatu lingkungan sebenarnya yang ditiru atau benar-benar suatu lingkungan yang hanya dalam imajinasi [11].

Akademik adalah keadaan orang-orang bisa menyampaikan dan menerima gagasan, pemikiran, ilmu pengetahuan, dan sekaligus dapat mengujinya secara jujur, terbuka dan leluasa.

Jadi virtual akademik adalah teknologi yang dapat membuat pengguna berinteraksi menyampaikan dan menerima gagasan, yang di simulasikan oleh komputer.

\section{c. Sensor Kinect 2}

Microsoft Kinect adalah perangkat yang menggunakan Gerakan penggunanya sebagai kontroler. Microsoft Kinect dari perangkat lunak teknologi yang dibangun oleh Rare, anak perusahaan dari Microsoft Game Studio [3]. Kinect memiliki sebuah kamera RGB, sensor kedalaman dan multi-array microphone yang dilengkapi software development kit [12]. Kinect mampu menyajikan pengenalan 3D pada seluruh tubuh dan juga kemampuan pengenalan suara. Kamera RGB ini membantu dalam pengenalan wajah dan filter deteksi lainnya dengan mendeteksi tiga komponen warna yaitu Red, Green, Blue. Microsoft menamakannya "RGB Camera" dengan mengacu pada tiga komponen warna tersebut. Depth sensor atau kedalaman merupakan sebuah proyektor infrared dan sensor monochrome CMOS yang bekerja secara bersama-sama untuk "melihat" ruangan atau area dalam bentuk 3D dengan tanpa memperdulikan kondisi cahaya [13]. Inputan Kinect biasanya berupa Gerakan pengguna yang akhirnya pengguna tidak perlu menyentuh secara langsung device controller, cukup dengan melakukan Gerakan-gerakan atau gesture.

Berdasarkan optical lenses, sensor kinect dapat bekerja pada kondisi sebagai berikut: (a) sudut pandang horizontal: $57^{\circ}$, (b) sudut pandang vertikal: $43^{\circ}$, (c) jarak kinect dengan user: 1.2 meter - 4 meter, (d) rentang kedalaman: $400 \mathrm{~mm}$ (mode dekat) $8000 \mathrm{~mm}$ (mode standar), (e) Suhu $5^{\circ}-35^{\circ}$ Celcius $\left(41^{\circ}-95^{\circ}\right.$ Fahrenheit) [5]. Gambar 1 menunjukan ilustrasi sendi-sendi tubuh manusia yang ditangkap oleh Kinect.

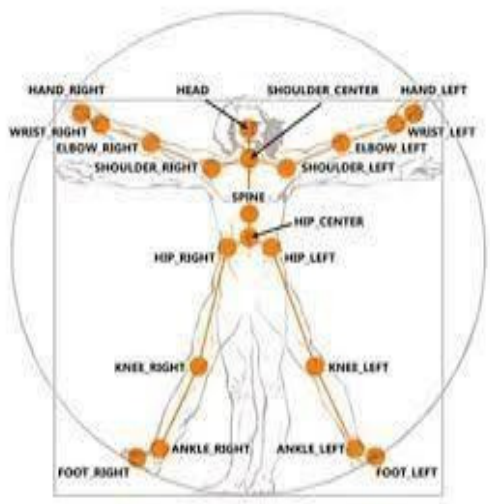

Gambar 1. Ilustrasi sendi-sendi tubuh manusia yang ditangkap oleh Kinect [5]

Struktur kinect mulai kiri kekanan adalah sensor, kamera dan light source yang digunakan menangkap citra RGB dan data kedalaman. Sensor kedalaman terdiri dari proyektor laser infrared yang dikombinasikan dengan sensor CMOS untuk menangkap data video dalam bentuk 3D pada kondisi cahaya sekitarnya. Jarak penginderaan sensor kedalaman dapat diatur, dan mampu melakukan kalibrasi pada sensor berdasarkan objek dan lingkungan fisik pemain.

Adapun fitur dari kinect:

a. light source inframerah

b. indikator lampu LED

c. kamera citra RGB

d. kamera infra merah untuk menangkap kedalaman data 
Resolusi maksimal kamera RGB 1280x960, sedangkan resolusi maksimal depth camera 640x480, kinect tampak seperti Gambar 2.

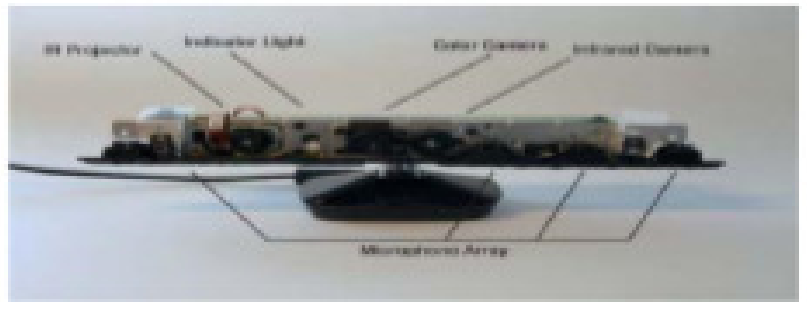

Gambar 2. Mesin Kinect [5]

Kamera RGB berfungsi mengenal wajah dan fitur deteksi lainnya dengan mendeteksi tiga komponen warna Red, Green, dan Blue. Kamera RGB ini mirip dengan webcam, yang dapat menangkap video pada resolusi 640x480 dengan warna 32bit pada 30 frames per detik. Beberapa resolusi dan frame standard yang dapat digunakan Kinect [5]:

1. Resolusi 640 x 480Fps30 dengan format RGB

2. Resolusi 1280x960Fps12 dengan format RGB

3. Resolusi 640x480Fps12 dengan format RAW YUV

4. Resolusi 640x480Fps15 dengan format YUV

Depth sensor terdiri atas kombinasi dari infrared laser projector dan monochrome CMOS sensor yang mengambil data video dalam 3D tanpa memperdulikan kondisi cahaya. Infrared pada Kinect tidak dapat dilihat secara kasat mata serta tidak berbahaya bagi tubuh manusia. Infrared mengirimkan ribuan sinar yang memantul untuk mengetahui objek yang ada didepannya (Mathe, Z., 2011). Sinar yang dihasilkan oleh infrared inilah yang ditangkap oleh kamera monochrome CMOS sensor dan mengukur waktu sinar yang ada setelah terpantul oleh objek yang ada di depannya. Hal ini memungkinkan Kinect untuk memetakan gambar 3D yang ada didepannya sampai kedalaman satu centimeter dan tiga milimeter untuk lebar dan tinggi [14].

\section{Metodologi Penelitian}

\subsection{Objek Penelitian}

Objek penelitian yang akan dibahas adalah dua orang mahasiswa yang berumur 23 tahun dengan jenis kelamin laki-laki dan perempuan.

\subsection{Metode Pengumpulan Data}

Pada penelitian ini untuk proses penyusunan laporan sampai pengujian dibutuhkan data-data yang menunjang proses penelitian. Metode pengumpulan data yang menunjang proses penelitian. Metode pengumpulan data yang digunakan dalam penelitian ini adalah pengambilan data scan model wajah 3D dengan sensor Kinect, melakukan studi literatur mencakup makalah, jurnal, skripsi yang berkaitan dengan topik penelitian ini.

\subsection{Spesifikasi Kebutuhan}

Spesifikasi kebutuhan perangkat keras dan perangkat lunak pada penelitian ini yaitu:

\subsubsection{Perangkat Keras(Hardware)}

$$
\text { Intel(R) Core }{ }^{\mathrm{TM}} \mathrm{i} 5 \text { - } 7400 \mathrm{CPU} @ 3,00 \mathrm{GHz} \text { (4 CPUs),-3,0GHz }
$$

RAM 8GB

VGA Full HD display

Kinect V2 


\subsubsection{Perangkat Lunak(Software)}

Perangkat lunak yang digunakan untuk mengembangkan avatar game "virtual akademik menggunakan sensor Kinect 2" ini diantaranya:

Windows 10

Blender 2.77

Microsoft Office Word 2013

Kinect SDK 2.0

\subsection{Pengujian}

Pengujian sistem merupakan tahap akhir dari pembuatan sistem. Ada berbagai model yang dapat digunakan dalam proses pengujian sistem. Metode yang akan digunakan yaitu :

System Usability Scale (SUS)

System Usability Scale merupakan kuisioner yang dapat digunakan untuk mengukur usability sistem komputer menurut sudut pandang subjektif pengguna. SUS terdiri dari 10 pertanyaan dengan menggunakan skala likert 1 sampai 5. Pertanyaan yang bernomol ganjil bernilai positif sedangkan pertanyaan yang bernomer genap bernilai negatif.

\subsection{Beberapa Kesalahan Umum}

- Kata "data" adalah jamak, bukan tunggal.

- Dalam bahasa Inggris Amerika, koma, semi / titik dua, titik, tanda tanya dan tanda seru terletak di dalam tanda kutip hanya ketika sebuah pemikiran atau nama lengkap dikutip, seperti judul atau kutipan penuh. Ketika tanda kutip digunakan, bukan tipografi tebal atau huruf miring, untuk menyorot kata atau frasa, tanda baca harus muncul di luar tanda kutip. Frasa atau pernyataan sisipan di akhir kalimat disisipkan di luar tanda kurung tutup (seperti ini). (Kalimat kurung disela di dalam tanda kurung.)

\section{Hasil Dan Pembahasan}

\subsection{Tahapan Penelitian}

\subsubsection{Citra RGB dan Depth dari sensor Kinect}

Citra adalah suatu cahaya pada bidang dua dimensi. Ditinjau dari sudut pandang matematis, citra merupakan fungsi kontinu dari intensitas cahaya pada bidang dua dimensi [15]. Sumber cahaya menerangi objek, kemudian objek memantulkan kembali sebagaian dari berkas cahaya tersebut. Pantulan cahaya ini ditangkap oleh alat-alat optimal, misalnya mata manusia, kamera, scanner, dan sebagainya, sehingga bayangan objek yang disebut citra terekam.

RGB adalah model warna pencahayaan yang dipakai untuk input devices seperti scanner maupun output devices seperti display monitor, warna-warna primernya seperti Red, Blue, Green tergantung pada teknologi yang dipakai seperti CCD atau PMT pada scanner atau digital camera, CRT atau LCD pada display monitor depth stream berisi sejumlah bingkai yang dimana piksel pada setiap bingkai mengandung informasi jarak dalam millimeter. Tiga resolusi yang didukung oleh depth stream adalah $640 \times 480$ piksel, 320 × 240 piksel, dan $80 \times 60$ piksel ke objek terdekat dari sama dengan bidang pandang kamera warna. Sensor kinect menggunakan IRemitter dan sensor.

IR depth yaitu sebuah sensor monokrom CMOS untuk menangkap informasi 3D dari sebuah objek. Proses pengambilan modelling wajah untuk avatar game dilakukan dengan model dihadapkan tepat didepan sensor kinect V2 dengan jarak $50 \mathrm{~cm}$ dari sensor kamera kinect, resolusi yang digunakan untuk pengambilan avatara adalah $640 \times 480$ pixel karena kebutuhan awal untuk pengambilan wajah avatar game dibutuhkan lebih besar dan kamera kinect V2 hanya mendukung resolusi 80 x 60, 320 x 240, 640 x 480. Tampilan dari pengambilan gambar terlihat seperti pada Gambar 3. 


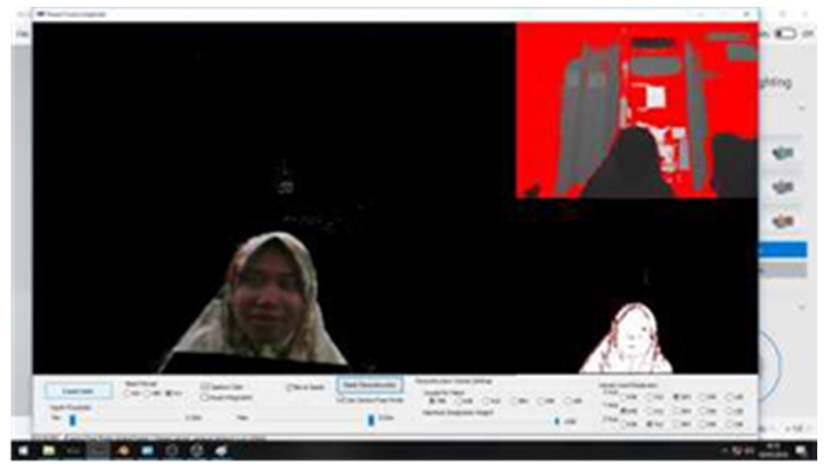

Gambar 3. Pengambilan wajah dari settingan citra RGB dan depth pada kinect

Gambar 3 menunjukkan proses pengambilan citra RGB menggunakan sensor kinect. Bagian 1 adalah tampilan objek atau model asli yang di capture oleh kinect. Bagian 2 adalah citra RGB hasil penangkapan atau rekam dari kinect. Bagian 3 adalah model hasil rekonstruksi.

\subsubsection{Rekonstruksi Wajah 3D dengan KinectFusion}

Rekonstruksi adalah membangun atau mengembalikan sesuatu berdasarkan kejadian semula, dimana dalam rekonstruksi tersebut terkandung nilai-nilai primer yang harus tetap ada dalam aktifitas membangun Kembali sesuatu sesuai dengan kondisi semula. Untuk kepentingan pembangunan Kembali sesuatu, apakah itu peristiwa, fenomena-fenomena sejarah masa lalu, hingga pada konsep pemikiran yang telah dikeluarkan oleh pemikiran-pemikiran terdahulu, kewajiban para rekonstruksi adalah memilih pada segala sisi, agar kemudian susatu yang coba dibangun Kembali sesuai dengan keadaan yang sebenarnya dan terhindar pada sebjektifitas yang berlebihan, dimana nantinya dapat mengaburkan substansi dari sesuatu yang ingin kita bangun tersebut, Hsil sensor wajah kinect dilihat pada Gambar 4.

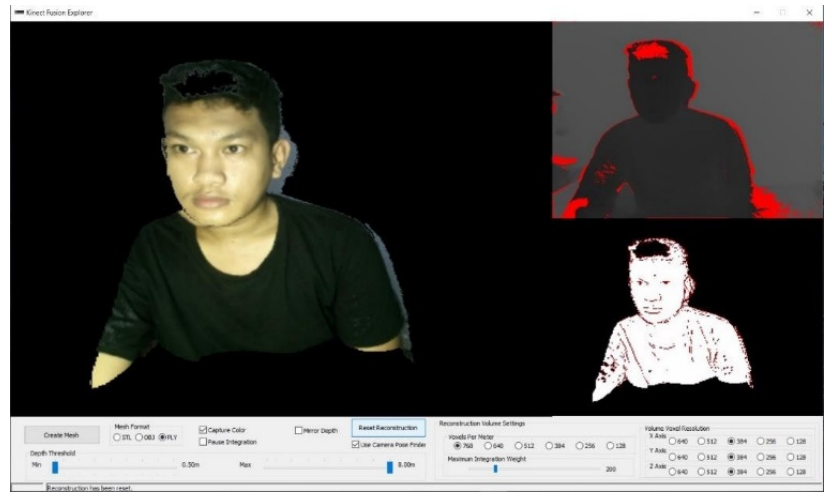

Gambar 4. Tampilan hasil sensor wajah kinect

\section{a. PLY}

Untuk menyimpan data 3D, berbagai property dapat disimpan termasuk warna dan transparansi, normal permukaan, koordinat tekstur dan nilai kepercayaan data, format yang sederhana dan mudah diterapkan tetapi cukup umum agar berguna untuk berbagai model.

b. Capture color

pemindaian objek untuk mengumpulkan data dan warna pada objek

c. Voxels permeter

Umum digunakan dalam pemodelan berbasis komputer dan simulasi grafis, susunan elemen volume yang membentuk ruang tiga dimensi nosional, terutama masing-masing dari array elemen diskrit dimana representasi dari objek tiga dimensi dibagi dan dihitung standar deviasi kumpulan tersebut. 


\subsubsection{Perbaikan Model Wajah}

Perbaikan model wajah adalah untuk menghaluskan objek yang masih belum sempurna yang diasilkan oleh sensor kemudian diberi tekstur dan penamaan objek.

\section{Reduksi Poligon Permukaan}

Reduksi polygon permukaan untuk menghaluskan atau meratakan bagian pada objek yang rusak atau tidak sempurna. Perhitungan polygon dalam objek dilakukan dengan fitur remesh pada blender, apabila polygon pada objek banyak maka texture yang di hasilkan akan besar, dan untuk polygon yang sudah sedikit dengan menggunakan filter remesh pada blender maka akan dihasilkan texture yang halus pada objek.

Proses export dari hasil aplikasi kinect V2 ke blender 3D untuk mengatur exture dan menghasilkan pada objek dapat dilihat seperti Gambar 5.

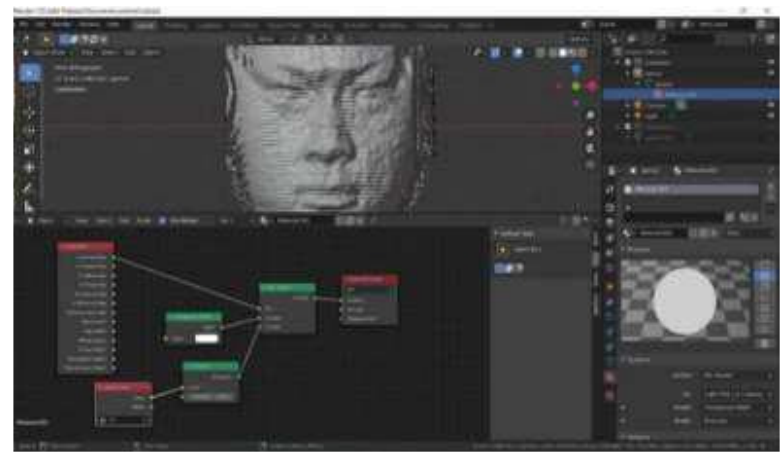

Gambar 5. Tampilan sensor wajah awal

Proses pengerjaan duplikat dalam blender adalah untuk menerapkan dan mengatur texture pada objek, proses duplikat dapat dilihat pada Gambar 6.

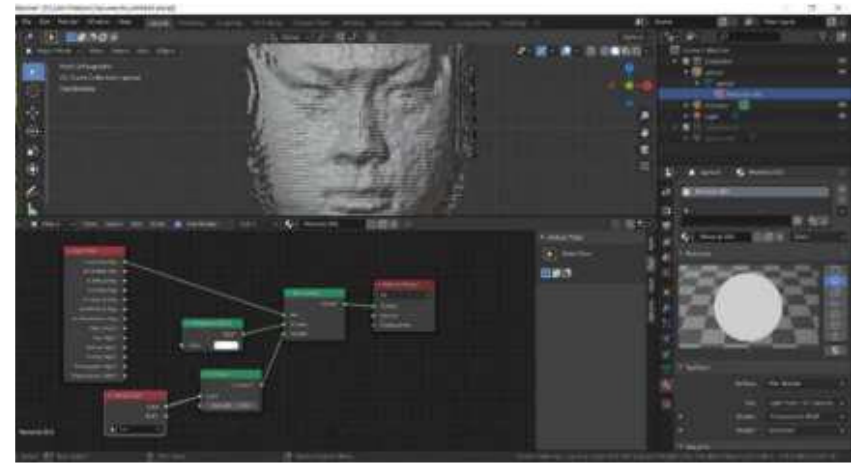

Gambar 6. Tampilan membuat duplikat

Proses pengerjaan selanjutnya adalah pemilihan layer untuk eksekusi texture pada objek dengan memilih layer duplikat yang telah dibuat sesuai inputan nama duplikat dan ditambah angka untuk menunjukan perbedaan layer asli dan duplikat yang dapat dilihat pada Gambar 7, setelah pemilihan layer duplikat tampilan pada blender akan seperti Gambar 6 dengan layer duplikat yang sudah dipilih. 


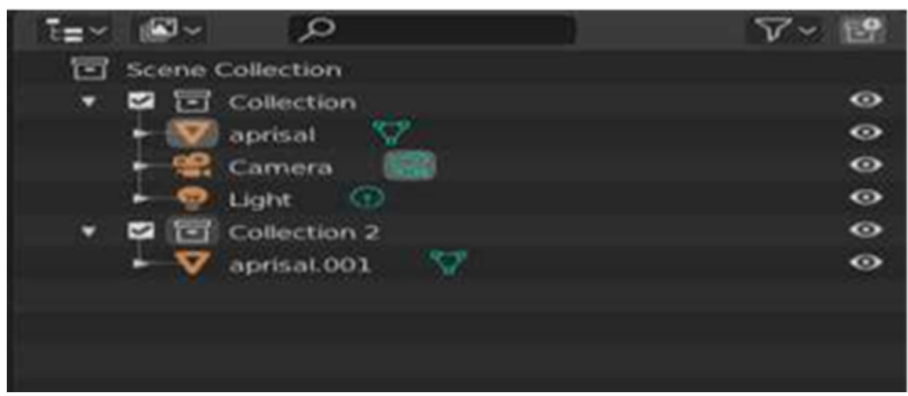

Gambar 7. Tampilan layer material

Proses pengerjaan selanjutnya adalah penghalusan objek dengan tools remesh pada blender untuk mendapatkan hasil yang lebih realistic dan tools remesh pada blender memperhalus semua bagian objek seperti pada Gambar 8.

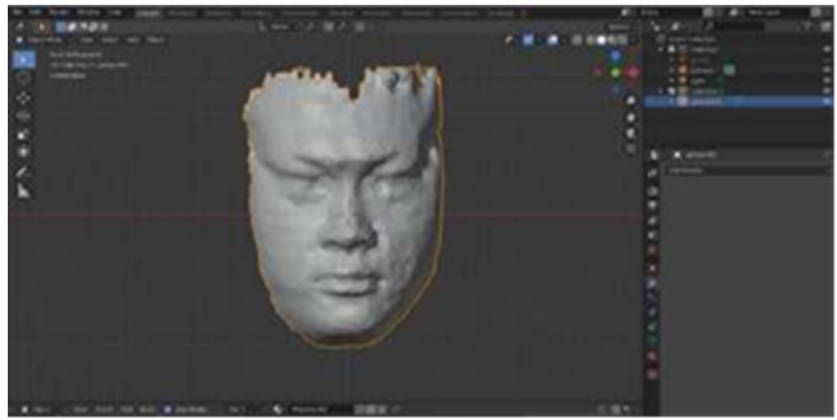

Gambar 8. Tampilan remesh

Jumlah polygon awal 3000, kemudian di reduksi menjadi 1500 polygon. Proses pengerjaan selanjutnya adalah uv smart maping atau pemberian texture pada objek untuk membentuk texture secara rapi dan tidak berantakan seperti pada bagian kiri Gambar 9.

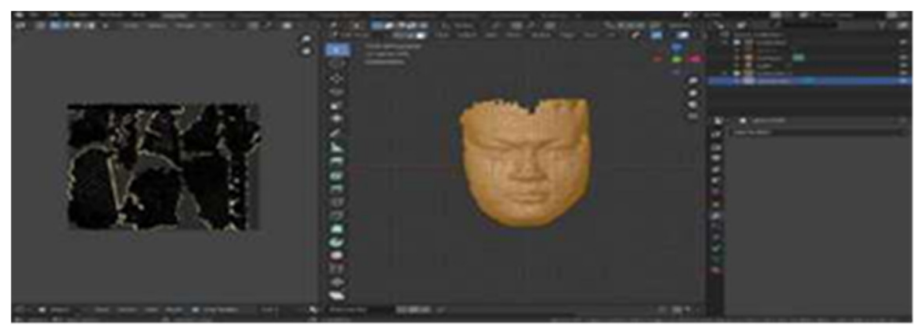

Gambar 9. Tampilan all select

Pada proses pengerjaan selanjutnya adalah penghalusan vertex pada objek sedikit berbeda dengan tools remesh yang hanya menghaluskan objek, tools vertex menghaluskan objek dengan bagian-bagian yang sudah dibagi uv smart maping. Untuk menggunakan tools vertex objek akan terlebih dahulu select all agar tools vertex dapat berjalan seperti pada Gambar 10.

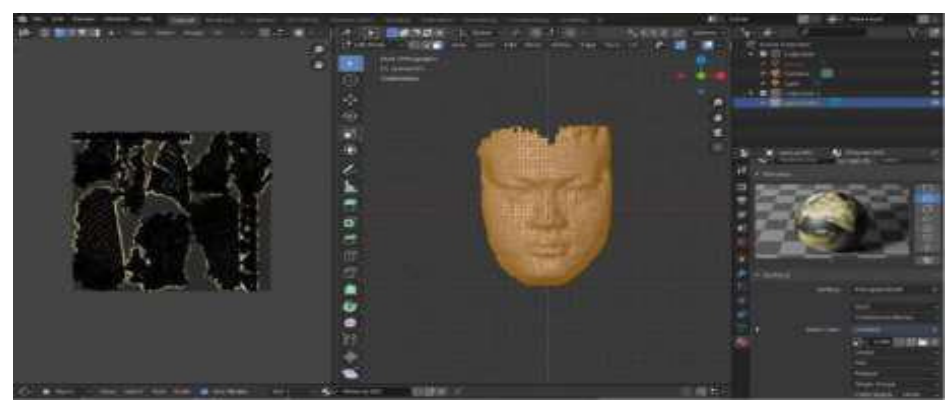

Gambar 10. Tampilan hasil penghalusan vertex 
Pada proses pengerjaan selanjutnya adalah bake objek menggabungkan objek yang sudah dibagi oleh tools uv smart maping menjadi 1 objek yang sudah dihaluskan dengan vertex dan akan menampilkan hasil dari penghalusan dan pemberian texture pada objek seperti pada Gambar 11.

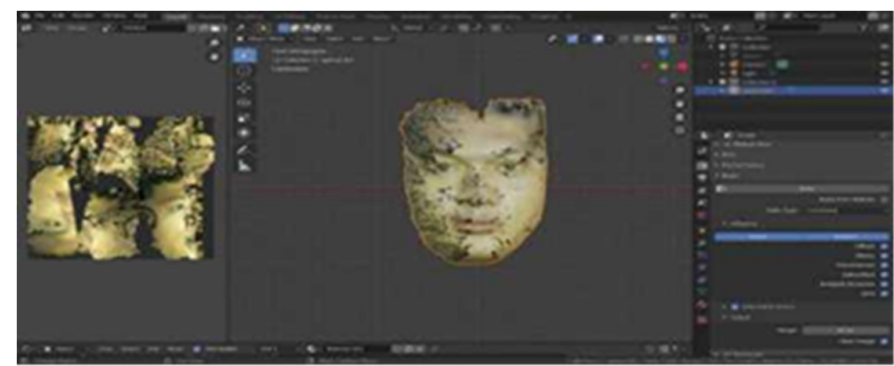

Gambar 11. Hasil render

\subsubsection{Model Wajah 3D(Topeng)}

Model wajah 3D adalah bentuk suatu benda-benda atau objek. Membuat dan mendesain objek tersebut sehingga terlihat seperti hidup. Level of Detail (LOD) merupakan konsep penting dalam pemodelan 3D yang menentukan tingkat abstraksi dari dunia nyata benda, terutama ditujukan untuk menggunakan jumlah optimal rincian benda dunia nyata sesuai dengan kebutuhan pengguna, dan aspek komputasi dan ekonomis.

Beberapa aspek yang harus dipertimbangkan bila membangun model objek, kesemuanya memberi kontribusi pada kualitas hasil akhir. Hal-hal tersebut meliputi metode untuk mendapatkan atau membuat data yang mendeskripsikan objek, tujuan dari model, tingkat kerumitan, perhitungan biaya, kesesuaian dan kenyamanan, serta kemudahan manupulasi model. Proses pemodelan 3D membutuhkan perancangan yang dibagi dengan beberapa tahapan untuk pembentukannya. Seperti objek apa yang ingin dibentuk sebagai objek dasar, metode pemodelan objek 3D, pencahayaan dan animasi objek sesuai dengan urutan proses yang akan dilakukan.

Untuk membentuk model wajah topeng 3D, melalui proses perbaikan model wajah membentuk texture, mengurangi polygon yang ada dalam objek sehingga menghasilkan topeng wajah 3D yang memiliki texture halus dengan polygon yang telah dikurangi. Untuk hasil dari metode wajah topeng dapat dilihat seperti Gambar 12

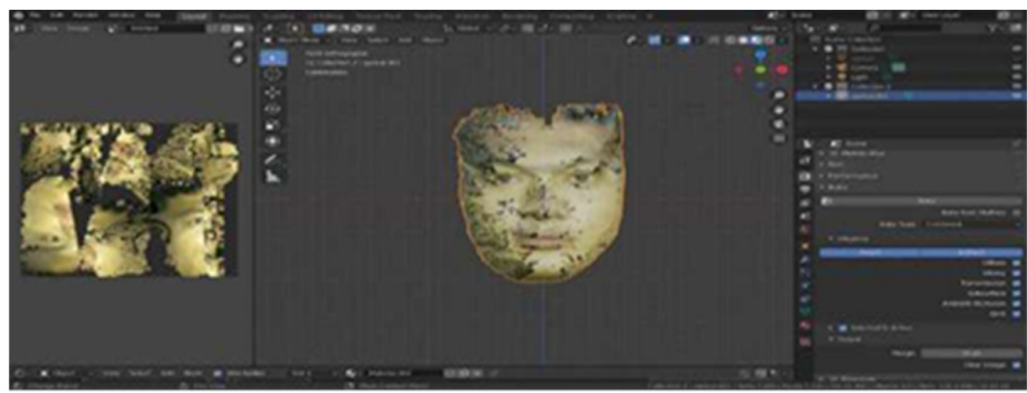

Gambar 12. Hasil dari pemodelan wajah untuk avatar game

\subsubsection{Hasil Pengujian}

Pengujian ini dilakukan untuk mengetahui apakah rekonstruksi pemodelan wajah sudah sesuai dengan kebutuhan. Pengujian ini dilakukan dengan pengujian kualitas, pengujian dilakukan oleh 9 orang mahasiswa dan 1 orang dosen.Pertanyaan dan skor masing-masing dapat dilihat pada Tabel 1.

Tabel 1. Hasil Pengujian

\begin{tabular}{lcccccccc}
\hline & \multicolumn{6}{c}{ JAWABAN } \\
\cline { 3 - 8 } No PERTANYAAN & SS & S & N & TS & STS & $\begin{array}{c}\text { Rata- } \\
\text { rata }\end{array}$ \\
\cline { 2 - 8 } & & 5 & 4 & 3 & 2 & 1 & \\
\hline
\end{tabular}

A. Membuka dan render tanpa masalah 
1. Apakah objek bisa dibuka di software pemodelan 3D

2. Apakah objek bisa dirender tanpa error $\quad 7 \quad 3 \quad 4,4$

B. Hanya segiempat dan segitiga

\begin{tabular}{lllll}
\hline 3. Apakah poligon objeknya hanya menggunakan & 6 & 4 & 3,6
\end{tabular} segiempat atau segitiga

C. Nama yang unik dan bermakna untuk objek, material dan tekstur

4. Apakah penamaan setiap komponen pada $\quad 6 \quad 4 \quad 3,6$ objek 3D sesuai dengan fungsinya

D. Model diletakkan di tengah/titik pusat

\begin{tabular}{lllll}
\hline 5. & Apakah objek berada pada pusat origin (titik & 7 & 3 & 4,4
\end{tabular} $0,0,0)$

\section{E. Kerapihan UVS}

\begin{tabular}{lllll}
\hline 6. & Apakah hasil pemetaan tekstur UV dari objek & 8 & 2 & 4,8
\end{tabular} rapi

\section{F. Resolusi tekstur disebutkan}

\begin{tabular}{llllll}
\hline 7. Apakah ukuran tekstur disebutkan & 8 & 2 & & 4,8 \\
8. & $\begin{array}{l}\text { Apakah jumlah 38 poligon sesuai dengan } \\
\text { kualitas tampilan objek }\end{array}$ & 6 & & 4 & 4,2 \\
\hline
\end{tabular}

\section{G. Kerealistisan Rendering}

$\begin{array}{lllll}\text { 9. } & \text { Apakah model 3D yang sudah dirender tampak } & 7 & 3 & 3,7\end{array}$ realistis atau mirip dengan aslinya

\begin{tabular}{cc} 
JUMLAH & 37,9 \\
RATA-RATA & 4,21 \\
\hline
\end{tabular}

$$
\text { Jumlah = Nilai Kuisioner X Jumlah Responden }
$$

Jumlah Responden

$$
\text { Rata }- \text { rata }=\quad \text { Jumlah }
$$

Jumlah Pertanyaan

Berdasarkan hasil kuisioner yang sudah di uji kualitas multimedia diatas, maka dapat kita ketahui yang menjawab

$$
\begin{aligned}
& \text { SS : } 8 \text { orang } \\
& \text { S : } 7 \text { orang } \\
& \mathrm{N}: 4 \text { orang }
\end{aligned}
$$

Maka berdasarkan hasil uji kualitas pemodelan ii mendapatkan nilai 41,6 dari skala 5, maka masuk kategori acceptable yang artinya aplikasi dapat diterima.

\section{Kesimpulan Dan Saran}

\subsection{Kesimpulan}

Berdasarkan hasil penelitian yang sudah dilakukan maka dapat diperoleh suatu kesimpulan sebagai berikut :

1. Telah dibuatnya model avatar game 3D berhasil menjadikan wajah menjadi avatar game 3D menggunakan sensor Kinect 
2. Hasil pengujian menunjukan bahwa model wajah avatar terlihat nyata. Berdasarkan nilai yang diperoleh dengan rata-rata 4.61 skala 5 maka aplikasi masuk kategori acceptable yang artinya system Usability Scale dapat diterima

\subsection{Saran}

Penelitian ini masih memiliki beberapa kekurangan, maka diharapkan adanya pengembangan lebih lanjut terhadap penelitian ini. Saran yang dapat digunakan sebagai acuan untuk pengembangan selanjutnya adalah belum sepenuhnya hasil sensor sama dengan wajah asli.

\section{Daftar Pustaka}

[1] L. V Fernandes, C. D. Castanho, and R. P. Jacobi, "A survey on game analytics in massive multiplayer online games," in 2018 17th Brazilian Symposium on Computer Games and Digital Entertainment (SBGames), 2018, pp. 21-2109.

[2] I. Lebres, P. Rita, S. Moro, and P. Ramos, "Factors determining player drop-out in Massive Multiplayer Online Games," Entertain. Comput., vol. 26, pp. 153-162, 2018.

[3] G. K. Bharathy, "Agent based human behavior modeling: A knowledge engineering based systems methodology for integrating social science frameworks for modeling agents with cognition, personality and culture," 2006.

[4] S. V. Filippov, "Blender software platform as an environment for modeling objects and processes of science disciplines," Prepr. Keldysh Inst. Appl. Math., pp. 230-242, 2018.

[5] B. Basir, Z. Zainuddin, and others, "Sistem Keamanan Rumah Berbasis Kinect," J. IT Media Inf. STMIK Handayani Makassar, vol. 8, no. 2, 2018.

[6] J. Jiao, L. Yuan, W. Tang, Z. Deng, and Q. Wu, "A post-rectification approach of depth images of Kinect v2 for 3D reconstruction of indoor scenes," ISPRS Int. J. Geo-Information, vol. 6, no. 11, p. 349, 2017.

[7] P. Henry, M. Krainin, E. Herbst, X. Ren, and D. Fox, "RGB-D mapping: Using Kinect-style depth cameras for dense 3D modeling of indoor environments," 2012, doi: 10.1177/0278364911434148.

[8] Z. Kang, J. Yang, Z. Yang, and S. Cheng, "A review of techniques for $3 \mathrm{~d}$ reconstruction of indoor environments," ISPRS Int. J. Geo-Information, vol. 9, no. 5, p. 330, 2020.

[9] R. Siv, I. Ardiyanto, and R. Hartanto, "3D human face reconstruction using depth sensor of Kinect 2," 2018.

[10] R. A. Kurniawan, "Rekonstruksi 3 Dimensi Dari Video Menggunakan Metode Structure-From-Motion (Studi Kasus: Wilayah Pertambangan Batubara)," Universitas Brawijaya, 2017.

[11] J. Mart'l'in-Gutiérrez, C. E. Mora, B. Añorbe-Dl'liaz, and A. González-Marrero, "Virtual technologies trends in education," EURASIA J. Math. Sci. Technol. Educ., vol. 13, no. 2, pp. 469-486, 2017.

[12] B. Çubukçu, U. Yüzgeç, R. Zileli, and A. Zileli, "Reliability and validity analyzes of Kinect V2 based measurement system for shoulder motions," Med. Eng. I\& Phys., vol. 76, pp. 20-31, 2020.

[13] Z. Zheng et al., "Hybridfusion: Real-time performance capture using a single depth sensor and sparse imus," in Proceedings of the European Conference on Computer Vision (ECCV), 2018, pp. 384-400.

[14] H. Hartono, L. Liliana, and R. Intan, "Pendeteksian Gerak Menggunakan Sensor Kinect for Windows," J. Infra, vol. 3, no. 2, p. pp-375, 2015.

[15] T. Zebua and E. Ndruru, "Pengamanan Citra Digital Berdasarkan Modifikasi Algoritma RC4," J. Teknol. Inf. dan IImu Komput., vol. 4, no. 4, pp. 275-282, 2017. 